\title{
VITAMIN D DEFICIENCY IN ACUTELY ILL PATIENTS
}

I Kostoglou-Athanassiou, E Pantazi, I Mavropoulos, O Skioti, G Katsoulis, D Kousouris, S Kontogiannis

Department of Endocrinology, Red Cross Hospital, Athens, Greece

$2^{\text {nd }}$ Department of Endocrinology, Alexandra Hospital, Athens, Greece

Acute Care Unit, Department of Internal Medicine, Alexandra Hospital, Athens, Greece

\section{OBJECTIVES}

\section{METHODS}

Vitamin D deficiency has been reported to be widely found within the population. Vitamin $D$ deficiency was also found to be prevalent in patients with autoimmune inflammatory diseases such as rheumatoid arthritis and systemic lupus erythematosus. Vitamin D deficiency was reported in almost all patients with acute myocardial infarction in a United States multicenter study. Low concentrations of 25-hydroxyvitamin $D \quad(25(\mathrm{OH}) \mathrm{D})$ are reported to be an independent risk factor for cardiovascular events, in particular for strokes and sudden cardiac deaths.

The aim was to study and report vitamin D levels in acutely ill patients being cared for in an acute care unit.

In 20 patients being cared for in an acute care unit and in 20 controls matched for age and sex $25(\mathrm{OH}) \mathrm{D}_{3}$ levels were measured. In the patient population CRP and procalcitonin were also measured. $25(\mathrm{OH}) \mathrm{D}_{3}$ was measured by radioimmunoassay, normal values being $47.7-114$ $\mathrm{nmol} / \mathrm{L}$.

\section{RESULTS}

In the patients being cared for in the acute care unit $25(\mathrm{OH}) \mathrm{D}_{3}$ levels were $30.33 \pm 3.63 \mathrm{nmol} / \mathrm{L}$ (mean $\pm S E M$ ), whereas in the controls $60.37 \pm 4.41 \mathrm{nmol} / \mathrm{L}(p<0.001$, Student's $t$ test). In the patients being cared for in the acute care unit vitamin $D$ deficiency or insufficiency was found 18 of the 20 patients.

\section{CONCLUSIONS}

Low vitamin $D$ levels were found in patients hospitalized in an acute care unit. These findings are in agreement with findings of other investigators having reported low levels of vitamin $D$ in patients with acute myocardial infarction. It has been proposed that low vitamin $D$ levels may be a risk factor for cardiovascular events and in patients with acute myocardial infarction may predict adverse outcomes. It has also been proposed that vitamin $D$ levels may decrease during the acute phase response, however, more studies are needed to confirm or refute this hypothesis. 